\title{
Dyssynchrony: a risk marker for ventricular arrhythmias?
}

\author{
Vineet Kumar, $M D^{a}$ \\ a Division of Cardiovascular Diseases, University of Alabama at Birmingham, Birmingham, AL
}

Received Oct 10, 2017; accepted Oct 10, 2017

doi:10.1007/s12350-017-1103-9

\section{See related article, pp. 555-569}

Mechanical left ventricular dyssynchrony can result from conduction system abnormalities like left bundle branch block (LBBB), scarring in the left ventricle from ischemic or non-ischemic cardiomyopathy, and significant left ventricular dilatation resulting in changes in gap junctions and ion channels thereby affecting conduction velocity. The end result of these processes is dyssynchronous contraction of the left ventricle, causing inefficient pump function. Resynchronization either by treatment of underlying pathology or cardiac resynchronization therapy (CRT) has been shown to improve mortality and morbidity in this patient population. ${ }^{1-4}$ In MADIT-CRT study, patients with LBBB who had improvement in their dyssynchrony with CRT were also less likely to experience ventricular arrhythmias compared to those who did not have an improvement. ${ }^{5}$ This raises the question if dyssynchronous contraction of the left ventricle is arrhythmogenic?

Dyssynchrony in patients with purely conduction system abnormality and no myopathy as seen in right ventricular pacing or LBBB with normal left ventricular structure and function does not seem to be associated with increased risk of arrhythmias. ${ }^{6,7}$ In the presence of abnormal substrate, several studies have showed increased risk of adverse cardiovascular outcomes in patients with dyssynchrony but data on arrhythmic events are less convincing. ${ }^{8-11}$ A sub-study of MADIT-

\footnotetext{
Reprint requests: Vineet Kumar, MD, Division of Cardiovascular Diseases, University of Alabama at Birmingham, 930 Faculty Office Towers, 510 20th Street South, Birmingham, AL 35294-0006; vkumar@uab.edu

J Nucl Cardiol 2018;25:570-1.

$1071-3581 / \$ 34.00$

Copyright ( 2017 American Society of Nuclear Cardiology.
}

CRT showed no difference in the occurrence of ventricular arrhythmias in patients undergoing CRT implantation with or without baseline dyssynchrony. ${ }^{10}$ In REVERSE trial there was no difference in occurrence of ventricular arrhythmias in patients with CRT ON vs CRT OFF implying resynchronization had little impact on occurrence of ventricular arrhythmias. The study population in this trial included patients with mild heart failure (NYHA classes I and II) with QRS greater than $120 \mathrm{~ms}$ and since there was no baseline assessment of dyssynchrony it is plausible that most of these patients did not have significant dyssynchrony to begin with. ${ }^{12}$ In the InSync ICD trial, there was reduction in ventricular arrhythmias, which was related to the degree of the remodeling after CRT implantation. ${ }^{13}$ Most of these studies used strain imaging to assess and quantify dyssynchrony, which, in itself is limited by temporal resolution of echocardiography.

In the current study, Saurabh et al studied the impact of dyssynchrony as assessed by phase analysis of gated SPECT on ventricular arrhythmias in patients undergoing CRT. There results showed that most ventricular arrhythmias occurred in patients with dyssynchrony and at least some degree of myocardial scarring. Reversal of dyssynchrony was seen in only few patients post CRT-implant and these patients had decreased risk of ventricular arrhythmias. There are several limitations of the study including small sample size, retrospective design, significantly poor response to CRT, and lack of effect on mortality despite higher incidence of ventricular arrhythmias. But in spite of these limitations, this study reaffirms the complex interaction between dyssynchrony and substrate. Myocardial fibrosis, change in myocardial fiber orientation and conduction properties as seen in significant LV dilation, may result in heterogeneous propagation of depolarization and thus induce or enhance mechanical dyssynchrony. Same heterogeneity also promotes reentry and thus increases the propensity to ventricular arrhythmias. 
Assessment of mechanical dyssynchrony can thus help us in risk stratification of patients with abnormal substrate. Absence of mechanical dyssynchrony may identify patients with less severe structural changes and subsequently lower risk of cardiovascular events and ventricular arrhythmias. Improvement in dyssynchrony may indicate improving substrate and serve as a marker for reverse remodeling. Further studies are needed to assess the contribution of myocardial substrate to dyssynchrony. Dyssynchrony assessment in patients with right ventricular pacing or LBBB pre- and postacute myocardial infarction may serve to better understand this complex interaction.

\section{Declaration}

I declare no conflict of interest.

\section{References}

1. Pouleur AC, Knappe D, Shah AM, Uno H, Bourgoun M, Foster E, McNitt S, et al Relationship between improvement in left ventricular dyssynchrony and contractile function and clinical outcome with cardiac resynchronization therapy: The MADITCRT trial. Eur Heart J 2011. doi:10.1093/eurheartj/ehr185.

2. Moss AJ, Hall WJ, Cannom DS, Klein H, Brown MW, Daubert JP, Estes NAM III, et al Cardiac-resynchronization therapy for the prevention of heart-failure events. N Engl J Med 2009. doi: 10.1056/NEJMoa0906431.

3. Cleland J, Freemantle N, Ghio S, Fruhwald F, Shankar A, Marijanowski M, Verboven M, et al Predicting the long-term effects of cardiac resynchronization therapy on mortality from baseline variables and the early response a report from the CARE-HF (Cardiac Resynchronization in Heart Failure) Trial. J Am Coll Cardiol 2008. doi:10.1016/j.jacc.2008.04.036.

4. Gorcsan J III, Oyenuga O, Habib PJ, Tanaka H, Adelstein EC, Hara $\mathrm{H}$, McNamara DM, et al Relationship of echocardiographic dyssynchrony to long-term survival after cardiac resynchronization therapy. Circulation 2010. doi:10.1161/CIRCULATIONAHA. 110.954768 .
5. Ouellet G, Huang DT, Moss AJ, Hall WJ, Barsheshet A, McNitt S, Klein $\mathrm{H}$, et al Effect of cardiac resynchronization therapy on the risk of first and recurrent ventricular tachyarrhythmic events in MADIT-CRT. J Am Coll Cardiol 2012. doi: 10.1016/j.jacc.2012.05.057.

6. Fahy GJ, Pinski SL, Miller DP, McCabe N, Pye C, Walsh MJ, Robinson K, et al Natural history of isolated bundle branch block. Am J Cardiol 1996;77:1185-90.

7. Kumar V, Venkataraman R, Aljaroudi W, Osorio J, Heo J, Iskandrian AE, Hage FG, et al Implications of left bundle branch block in patient treatment. Am J Cardiol 2013. doi: 10.1016/j.amjcard.2012.09.029.

8. Tsai SC, Chang YC, Chiang K-F, Lin W-Y, Huang J-L, Hung G$\mathrm{U}, \mathrm{Kao} \mathrm{C}-\mathrm{H}$, et al LV dyssynchrony is helpful in predicting ventricular arrhythmia in ischemic cardiomyopathy after cardiac resynchronization therapy: A preliminary study. Medicine (Baltim) 2016. doi:10.1097/MD.0000000000002840.

9. Penicka M, Bartunek J, Lang O, Medilek K, Tousek P, Vanderheyden M, De Bruyne B, et al Severe left ventricular dyssynchrony is associated with poor prognosis in patients with moderate systolic heart failure undergoing coronary artery bypass grafting. J Am Coll Cardiol 2007. doi:10.1016/j.jacc.2007.03.070.

10. Kutyifa V, Pouleur AC, Knappe D, Al-Ahmad A, Gibinski M, Wang PJ, McNitt S, et al Dyssynchrony and the risk of ventricular arrhythmias. JACC Cardiovasc Imaging 2013. doi: 10.1016/j.jcmg.2012.12.008.

11. Cho GY, Song JK, Park W-J, Han S-W, Choi S-H, Doo Y-C, Oh D-J, et al Mechanical dyssynchrony assessed by tissue Doppler imaging is a powerful predictor of mortality in congestive heart failure with normal QRS duration. J Am Coll Cardiol 2005. doi: 10.1016/j.jacc.2004.11.074.

12. Barsheshet A, Wang PJ, Moss AJ, Solomon SD, Al-Ahmad A, McNitt S, Foster E, et al Reverse remodeling and the risk of ventricular tachyarrhythmias in the MADIT-CRT (Multicenter Automatic Defibrillator Implantation Trial-Cardiac Resynchronization Therapy). J Am Coll Cardiol 2011. doi: 10.1016/j.jacc.2010.12.041.

13. Di Biase L, Gasparini M, Lunati M, Santini M, Landolina M, Boriani G, Curnis A, et al Antiarrhythmic effect of reverse ventricular remodeling induced by cardiac resynchronization therapy: The InSync ICD (Implantable Cardioverter-Defibrillator) Italian Registry. J Am Coll Cardiol 2008. doi:10.1016/j.jacc.2008.07.043. 